\title{
A Clinical study of amniotic fluid index at or beyond 28 weeks of gestation and its relation to perinatal outcome
}

\author{
Monica Chetani $^{1}$, Deepika ${ }^{2 *}$, Santosh Khajotia ${ }^{3}$, Swati Kochar ${ }^{3}$
}

\begin{abstract}
${ }^{1}$ Department of Obstetrics and Gynaecology, FNB Trainee Institute of Reproductive Medicine, Kolkata, India ${ }^{2}$ Department of Obstetrics and Gynaecology, ESI PGIMSR, Basaidarapur, New Delhi, India

${ }^{3}$ Department of Obstetrics and Gynaecology, Sardar Patel Medical College, Bikaner, Rajasthan, India
\end{abstract}

Received: 18 June 2017

Accepted: 23 June 2017

\author{
*Correspondence: \\ Dr. Deepika, \\ E-mail: lhmcdeepika@gmail.com
}

Copyright: ( ) the author(s), publisher and licensee Medip Academy. This is an open-access article distributed under the terms of the Creative Commons Attribution Non-Commercial License, which permits unrestricted non-commercial use, distribution, and reproduction in any medium, provided the original work is properly cited.

\begin{abstract}
Background: Amniotic fluid plays a major role in the development of fetus. It provides a medium in which fetus can readily move, cushions the fetus against injuries, helps to maintain even temperature. Objective of present study was to investigate the perinatal outcome of ultrasonographically detected normal and decreased (Oligohydramnios) amniotic fluid index, at or beyond 28 weeks of gestation.

Methods: During this study 200 patients with singleton pregnancy were selected at or beyond 28 weeks of pregnancy and AFI was evaluated. On the basis of AFI measurement patients were divided in two groups. Perinatal outcome in pregnancies with AFI of $<5 \mathrm{~cm}$ were compared with those with normal AFI.

Results: There was significant correlation $(p<0.001)$ between oligohyramnios and poor perinatal outcome. Incidence of LSCS, meconium stained liquor and low apgar score has significant correlation in patients with oligohydramnios. Incidence of low birth weight babies, NICU admissions and perinatal death was more were more are more in oligohydramnios cases. This is statistically significant $(\mathrm{p}<0.001)$.

Conclusions: AFI $<5 \mathrm{~cm}$ at or beyond 28 weeks of gestational age in an indicator of poor perinatal outcome. AFI measurement in antepartum or intrapartum period can help to identify women who need increased antepartum surveillance for pregnancy complications and such women should be managed in a special unit to combat the complications effectively.
\end{abstract}

Keywords: Amniotic fluid, Gestation, Oligohydramnios

\section{INTRODUCTION}

Amniotic fluid plays a major role in the development of fetus. It provides a medium in which fetus can readily move, cushions the fetus against injuries, helps to maintain even temperature. It also plays a role in dilatation of cervix during labour. Adequate amniotic fluid helps in permitting extension of limbs and prevents joint contractures. It prevents the compression of the umbilical cord, placenta and protects the fetus from vascular and nutritional compromises. In 1989, Brace and
Wolf demonstrate a progressive increase in the AFV from 10 to 22 weeks gestation. ${ }^{1}$ From 22 to 39 weeks gestation the AFV remained stable (averaging $777 \mathrm{ml}$ with a $95 \%$ confidence interval of 302 to $1997 \mathrm{ml}$ ) and then gradually declined. Amniotic fluid is approximately $7 \mathrm{ml}$ at 8 weeks, $30 \mathrm{ml}$ by 10 weeks, $190 \mathrm{ml}$ by 16 weeks and mean of $780 \mathrm{ml}$ by $32-35$ weeks then decreasing to about 400 $450 \mathrm{ml}$ by 42 weeks.

After 40 weeks amniotic fluid decreases at a rate of $8 \%$ per week and averages only $400-450 \mathrm{ml}$ at the end of the 
42 weeks. It reduces further to a mean of $250 \mathrm{ml}$ and $160 \mathrm{ml}$ at 43 and 44 weeks respectively. The net turnover of amniotic fluid is about $1000 \mathrm{ml} /$ day. ${ }^{2}$ Abnormalities of the amniotic fluid volume can interfere directly with the fetal development or may be an indirect sign of underlying disorder. Oligohydramnios can be associated with fetal congenital anomalies and Intrauterine Growth Retardation (IUGR). It is usually directly proportional to the degree of IUGR and it indicates placental dysfunction. Oligohydramnios can also cause asymmetrical fetal growth, contracture of the joints and hypoplasia of fetal lungs by decreasing the lung expansion due to compression of the fetal abdomen which limits the movements of the fetal diaphragm and decreases the flow of the amniotic fluid into and out of the fetal lung. Over the past decades, a number of sonographic methods have been used to measure the amniotic fluid. Phelan et al described quantification of amniotic fluid using the amniotic fluid index (AFI). ${ }^{2}$ The four-quadrant technique termed AFI is in which a vertical pocket of amniotic fluid, free of umbilical cord, in each of four equal uterine quadrant was summated.

\section{Oligohydramnios}

An amniotic fluid volume more than two standard deviation below the mean for specific gestational age or volume reduced below the 5th percentile for particular gestational age would define Oligohydramnios. Based on this definition, volume $<300 \mathrm{ml}$ at term would constitute Oligohydramnios. According to Phelan et al Oligohydraminos is defined by AFI $<5 \mathrm{~cm}$. $^{2}$

Objective of present study was to investigate the perinatal outcome of ultrasonographically detected normal and decreased (Oligohydramnios) amniotic fluid index, at or beyond 28 weeks of gestation.

Amniotic fluid indices as described by Phelan et al are Given in Table $1 .^{3}$

Table 1: Amniotic fluid indices

\begin{tabular}{|ll|}
\hline AFV & AFI $(\mathrm{cm})$ \\
\hline Oligohydramnios & $<5$ \\
\hline Borderline & $5.1-8$ \\
\hline Normal & $8.1-24.0$ \\
\hline Polyhydramnios & $>24$ \\
\hline
\end{tabular}

\section{METHODS}

The study was conducted in Department of Obstetrics and Gynaecology, P.B.M. Hospital, Sardar Patel Medical College, Bikaner. During this study 200 patients with singleton pregnancy were selected at or beyond 28 weeks of pregnancy and AFI was evaluated in those patients with technique of Phelan et al. ${ }^{2}$

AFI $<5 \mathrm{~cm}$ at or beyond 28 weeks of gestational age in an indicator of poor perinatal outcome. On the basis of AFI measurement patients were divided in two groups. Group one, those who had AFI $<5 \mathrm{~cm}$ and group 2 with normal AFI $(8-24 \mathrm{cms})$. Perinatal outcome in pregnancies with AFI of $<5 \mathrm{~cm}$ were compared with those with normal AFI. Finally, AFI was evaluated as predictor of neonatal outcome by calculated $\%$ positive and negative predictive value of AFI for the selected outcomes. On the basis of AFI measurement patients were divided in two groups. Group one, those who had AFI $<5 \mathrm{~cm}$ and group 2 with normal AFI $(8-24 \mathrm{cms})$. Perinatal outcome in pregnancies with AFI of $<5 \mathrm{~cm}$. were compared with those with normal AFI. Finally, AFI was evaluated as predictor of neonatal outcome by calculated $\%$ positive and negative predictive value of AFI for the selected outcomes.

Pregnant women with gestational age of 28 weeks or beyond attending ANC clinic, labour room, booked and unbooked patients were included in the study. It was a comparative non-randomized study.

Sample Size was

- Group 1 Oligohydramnios - 100

- Group 2 Normal AFI - 100

\section{Inclusion criteria}

- All pregnant women with gestation age of 28 weeks or more, willing to participate in the study are included with written and informed consent.

\section{Exclusion criteria}

- $\quad$ Pregnant women with gestation age of less than 28 weeks

- Polyhydramnios

- Multiple pregnancy

- Placenta previa

- Fetal congenital anomalies

- Patients with ruptured membranes

- Abnormal presentations and positions

Technique of amniotic fluid index assessment

- Supine position.

- A linear, curvilinear or sector transducer can be used.

- Divide the uterus into 4 quadrants using the maternal sagittal midline vertically and an arbitrary transverse line approximately halfway between symphysis pubis and upper edge of uterine fundus.

- Transducer must be kept parallel to the maternal sagittal plane and perpendicular to the maternal coronal plane throughout.

- The deepest unobstructed (free of umbilical cord or fetal parts) and clear pocket of amniotic fluid is visualized and the image frozen. Ultrasound calipers are manipulated to measure the pocket in a strictly vertical direction. 
- The process was repeated in each four quadrants and pocket measurement summed, which gives AFI. If AFI is less than 8, perform the four quadrant evaluation 3 times and average the values.

The end points used to judge perinatal outcome are:

- Fetal distress predicted by abnormal FHR, meconium stained liquor.

- One minute and 5 minute Apgar score judged by paediatrician APGAR score less than 7 will be considered as abnormal.

- Frequency of admission to NICU

- IUGR- baby weight of less than 10th percentile for gestation age

- Perinatal mortality.

\section{RESULTS}

The present study was conducted in Department of Obstetrics and Gynaecology, S.P. Medical College and Associated Group of Hospitals, Bikaner, consisting of 200 patients.

In which 100 patients having AFI $<5$ were labeled as study group and 100 patients having normal AFI (8$24 \mathrm{cms}$ ). Cases were selected by taking into consideration all inclusion and exclusion criteria.

In this study, following observation were drawn:

Table 2: Distribution of cases according to maternal age group (years) between study and control groups.

\begin{tabular}{|l|llll|}
\hline $\begin{array}{l}\text { Age group } \\
\text { (years) }\end{array}$ & $\begin{array}{l}\text { Study group } \\
\text { No. of } \\
\text { cases }\end{array}$ & $\begin{array}{l}\text { Control group } \\
\text { No. of } \\
\text { cases }\end{array}$ & $\%$ \\
\hline$\leq 20$ & 29 & 29.0 & 12 & 12.0 \\
\hline $21-25$ & 58 & 58.0 & 68 & 68.0 \\
\hline $26-30$ & 10 & 10.0 & 18 & 18.0 \\
\hline$>30$ & 3 & 3.0 & 2 & 2.0 \\
\hline Total & 100 & 100 & 100 & 100 \\
\hline Mean & 22.87 & & 23.58 & \\
\hline SD & 3.38 & & 3.20 & \\
\hline T & 1.525 & & & \\
\hline
\end{tabular}

The distribution of cases according to maternal age group (years) between Study and Control groups. Most common age group in the present study was 21-25 years, 58 cases were in study group and 68 cases were in control group (Table 2).

According to antenatal booking status, 60 females in study group and 71 females in control group were booked while 40 females in study group and 29 females in control group were unbooked.

On applying chi square test, the difference was found to be statistically insignificant ( $p>0.05)$. Mean age in study group was $22.87 \pm 3.38$ and in control group was $23.58 \pm 3.20$ and the difference was found to be insignificant $(\mathrm{p}>0.05)$ (Table 3).

Table 3: Distribution of cases according to antenatal booking status between study and control groups.

\begin{tabular}{|l|llll|}
\hline Booked/unbookd & $\begin{array}{l}\text { Study group } \\
\text { No. of } \\
\text { cases }\end{array}$ & $\begin{array}{l}\text { Control group } \\
\text { No. of } \\
\text { Cases }\end{array}$ & $\%$ \\
\hline Booked & 60 & 60.0 & 71 & 71.0 \\
\hline Unbooked & 40 & 40.0 & 29 & 29.0 \\
\hline Total & 100 & 100 & 100 & 100 \\
\hline$\chi^{2}$ & 2.677 & & & \\
\hline P & 0.102 & & & \\
\hline
\end{tabular}

Table 4: Distribution of cases according to gravidity between study and control groups.

\begin{tabular}{|lllll|}
\hline Gravida & \multicolumn{2}{l}{$\begin{array}{l}\text { Study group } \\
\text { No. of } \\
\text { cases }\end{array}$} & $\begin{array}{l}\text { Control group } \\
\text { No. of } \\
\text { cases }\end{array}$ & $\%$ \\
\hline 1 & 63 & 63 & 59 & 59 \\
\hline 2 & 18 & 18.0 & 19 & 19.0 \\
\hline 3 & 5 & 5.0 & 11 & 11.0 \\
\hline$>4$ & 14 & 14.0 & 11 & 11.0 \\
\hline Total & 100 & 100 & 100 & 100 \\
\hline Mean & 1.81 & & 1.74 & \\
\hline SD & 1.38 & & 1.04 & \\
\hline T & 0.404 & & & \\
\hline P & 0.686 & & & \\
\hline
\end{tabular}

According to gravidity, 63 females in study group and 59 females in control group were primigravida, 18 and 19 females in study and control groups were 2nd gravida respectively, 5 and 11 females of study and control group were 3rd gravida respectively while 14 cases in study group and 11 cases in control group were of gravida $\geq 4$. On applying chi square test, the difference was found to be statistically insignificant( $p>0.05$ ) (Table 4$)$.

Table 5: Distribution of cases according to gestational age (weeks) between study and control groups.

\begin{tabular}{|c|c|c|c|c|}
\hline \multirow[b]{2}{*}{ Gestational Age } & \multicolumn{2}{|c|}{ Study group } & \multicolumn{2}{|c|}{ Control group } \\
\hline & $\begin{array}{l}\text { No. of } \\
\text { cases }\end{array}$ & $\%$ & $\begin{array}{l}\text { No. of } \\
\text { cases }\end{array}$ & $\%$ \\
\hline 28-29 weeks+6 days & 1 & 1.0 & 0 & - \\
\hline $30-31$ weeks+6 days & 2 & 2.0 & 0 & - \\
\hline $32-33$ weeks +6 days & 2 & 2.0 & 0 & - \\
\hline $34-35$ weeks +6 days & 4 & 4.0 & 2 & 2.0 \\
\hline 36-37 weeks+6 days & 16 & 16.0 & 10 & 10.0 \\
\hline $38-39$ weeks+6 days & 44 & 44.0 & 58 & 58.0 \\
\hline $40-42$ weeks & 31 & 31.0 & 30 & 30.0 \\
\hline Total & 100 & 100 & 100 & 100 \\
\hline Mean & 38.18 & & 38.70 & \\
\hline SD & 2.35 & & 1.33 & \\
\hline $\mathrm{T}$ & 1.929 & & & \\
\hline $\mathrm{P}$ & 0.055 & & & \\
\hline
\end{tabular}


Mean gestational age in study group was $38.18 \pm 2.35$ weeks while in control group it was $38.70 \pm 1.33$ weeks and the difference was found to be statistically insignificant $(\mathrm{p}>0.05)$ (Table 5).

Table 6: Distribution of cases according to onset of labour between study and control groups.

\begin{tabular}{|c|c|c|c|c|}
\hline \multirow[b]{2}{*}{ Labour } & \multicolumn{2}{|c|}{ Study group } & \multicolumn{2}{|c|}{ Control group } \\
\hline & $\begin{array}{l}\text { No. of } \\
\text { Cases }\end{array}$ & $\%$ & $\begin{array}{l}\text { No. of } \\
\text { Cases }\end{array}$ & $\%$ \\
\hline Spontaneous & 48 & 48.0 & 73 & 73.0 \\
\hline Induced & 52 & 52.0 & 27 & 27.0 \\
\hline Total & 100 & 100 & 100 & 100 \\
\hline$\chi^{2}$ & 13.077 & & & \\
\hline $\mathrm{P}$ & $<0.001$ & & & \\
\hline
\end{tabular}

Table 6 shows distribution of cases according to Onset of Labour in study and control groups. 52 females of study group and 27 females of control group needed induction of labour. Spontaneous onset of labour was observed in $48 \%$ cases in study group and $73 \%$ cases in control group.

Table 7: Distribution of cases according to nature of amniotic fluid between study and control groups.

\begin{tabular}{|l|l|lll|}
\hline $\begin{array}{l}\text { Nature of } \\
\text { amniotic fluid }\end{array}$ & $\begin{array}{l}\text { Study group } \\
\text { No. of } \\
\text { cases }\end{array}$ & $\%$ & $\begin{array}{l}\text { Control group } \\
\text { No. of } \\
\text { cases }\end{array}$ & $\%$ \\
\hline Clear & 54 & 54.0 & 80 & 80.0 \\
\hline Thick MSL & 6 & 6.0 & 2 & 2.0 \\
\hline Thin MSL & 40 & 40.0 & 18 & 18.0 \\
\hline Total & 100 & 100 & 100 & 100 \\
\hline$\chi^{2}$ & 15.390 & & & \\
\hline P & $<0.001$ & & & \\
\hline
\end{tabular}

On applying chi square test, the difference was found statistically highly significant $(\mathrm{p}<0.001)$ which implies that more patients with oligohyramnios were induced.

Majority of females had clear amniotic fluid (54\% study group and $80 \%$ control group). Thick MSL was present in 8 females and out of them 6 cases were in study group and 2 belonged to control group. Thin MSL was present in 58 females and out of them 40 and 18 were belonged to study group and control group respectively and this difference was found to be statistically highly significant $(p<0.001)$. This suggests that meconium stained liquor was more in oligohydromnios group (Table 7).

According to Mode of delivery, $45 \%$ cases in study group and $76 \%$ cases in control group had normal vaginal delivery while $54 \%$ cases in study group and $23 \%$ cases in control group had LSCS. Only 2 females had forceps delivery and out of them 1 each belonged to study and control groups. On applying chi square test, the difference was found to be statistically highly significant $(\mathrm{p}<0.001)$. Rate of LSCS was more in oligohydramniosgroup (Table 8).

Table 8: Distribution of cases according to mode of delivery between study and control groups.

\begin{tabular}{|c|c|c|c|c|}
\hline \multirow{2}{*}{$\begin{array}{l}\text { Mode of } \\
\text { delivery }\end{array}$} & \multicolumn{2}{|c|}{ Study group } & \multicolumn{2}{|c|}{ Control group } \\
\hline & $\begin{array}{l}\text { No. of } \\
\text { cases }\end{array}$ & $\%$ & $\begin{array}{l}\text { No. of } \\
\text { cases }\end{array}$ & $\%$ \\
\hline Normal vaginal & 45 & 45.0 & 76 & 76.0 \\
\hline Forceps & 1 & 1.0 & 1 & 1.0 \\
\hline LSCS & 54 & 54.0 & 23 & 23.0 \\
\hline Total & 100 & 100 & 100 & 100 \\
\hline$\chi^{2}$ & 20.423 & & & \\
\hline $\mathrm{P}$ & $<0.001$ & & & \\
\hline
\end{tabular}

Table 9: Various indications of LSCS between study and control groups.

\begin{tabular}{|c|c|c|c|c|}
\hline \multirow[b]{2}{*}{ Indication } & \multicolumn{2}{|c|}{ Study group } & \multicolumn{2}{|c|}{ Control group } \\
\hline & $\begin{array}{l}\text { No. of } \\
\text { cases }\end{array}$ & $\%$ & $\begin{array}{l}\text { No. of } \\
\text { cases }\end{array}$ & $\%$ \\
\hline Fetal distress & 30 & 55.6 & 5 & 21.7 \\
\hline IUGR & 16 & 29.6 & 2 & 8.7 \\
\hline $\begin{array}{l}\text { PROM with } \\
\text { non progress of } \\
\text { labour }\end{array}$ & 2 & 3.7 & 4 & 17.4 \\
\hline CPD & 0 & 0 & 3 & 13.1 \\
\hline $\begin{array}{l}\text { Failure of } \\
\text { induction }\end{array}$ & 2 & 3.7 & 4 & 17.4 \\
\hline $\begin{array}{l}\text { Previous LSCS } \\
\text { in labour }\end{array}$ & 4 & 7.4 & 5 & 21.7 \\
\hline
\end{tabular}

According to various indications of LSCS; fetal distress was present in $55.6 \%$ cases in study and $21.7 \%$ cases in control group. IUGR was present in 16 cases of study and 2 cases of control group Fetal distress leading to LSCS is more in oligohydramniosgroup (Table 9).

Table 10: Distribution of cases according to fetal outcome between study and control groups.

\begin{tabular}{|l|llll|}
\hline Fetal & \multicolumn{2}{l}{ Study group } & \multicolumn{2}{l|}{ Control group } \\
\hline outcome & No. of cases & \% & No. of cases & \% \\
\hline Live & 94 & 94 & 99 & 99 \\
\hline Still Birth & 5 & 5.0 & 1 & 1.0 \\
\hline IUD & 1 & 1.0 & 0 & - \\
\hline Total & 100 & 100 & 100 & 100 \\
\hline$\chi 2$ & 3.796 & & & \\
\hline P & 0.150 & & & \\
\hline
\end{tabular}

According to fetal outcome, out of total 200 babies there were 7 fetal death, out of them 6 were in study group and 1 was from control group. The difference was found statistically insignificant $(p>0.05)$. The reason to this may be due to small number of patients in present study (Table 10). 
According to Apgar score at 1 minute 33 cases in study group and 18 cases in control group had apgar score $<7$. The difference was found to be statistically significant $(\mathrm{p}<0.05) .14$ cases in study group and 4 cases in control group belonged to Apgar score $\leq 7$ at 5 minutes. This difference was also found to be significant $(\mathrm{p}<0.01)$. Low Apgar score was observed in oligohydroamnios group (Table 11).

Table 11: Distribution of cases according to Apgar Score between study and control groups.

\begin{tabular}{|lllllll|}
\hline & Study Group & \multicolumn{2}{c}{ Control Group } & \multicolumn{2}{c}{} & P \\
\hline At 1 minute & No. of cases & $\%$ & No. of cases & \% & $\chi^{2}$ & $<0.05$ \\
\hline At 5 Minutes & 33 & 33.0 & 18 & 18.0 & 5.9218 & $<0.01$ \\
\hline
\end{tabular}

Table 12: Distribution of cases according to baby birth weight (kg) between study and control groups.

\begin{tabular}{|c|c|c|c|c|}
\hline \multirow{2}{*}{$\begin{array}{l}\text { Birth } \\
\text { weight } \\
\text { (kg) }\end{array}$} & \multicolumn{2}{|c|}{ Study group } & \multicolumn{2}{|c|}{ Control group } \\
\hline & $\begin{array}{l}\text { No. of } \\
\text { cases }\end{array}$ & $\%$ & $\begin{array}{l}\text { No. of } \\
\text { cases }\end{array}$ & $\%$ \\
\hline $1.0-1.5$ & 4 & 4.0 & 0 & - \\
\hline $1.6-2.0$ & 2 & 2.0 & 0 & - \\
\hline $2.1-2.5$ & 36 & 36.0 & 22 & 22.0 \\
\hline $2.6-3.0$ & 43 & 43.0 & 51 & 51.0 \\
\hline $3.1-3.5$ & 15 & 15.0 & 26 & 26.0 \\
\hline$>3.5$ & 0 & - & 1 & 1.0 \\
\hline Total & 100 & 100 & 100 & 100 \\
\hline Mean & 2.65 & & 2.86 & \\
\hline SD & 0.43 & & 0.31 & \\
\hline $\mathrm{T}$ & 3.991 & & & \\
\hline $\mathrm{P}$ & $<0.001$ & & & \\
\hline
\end{tabular}

Table 12 shows distribution of cases according to baby birth weight $(\mathrm{kg})$ in relation to study and control groups. Mean birth weight in study group was $2.65 \pm 0.43$ and in control group was $2.86 \pm 0.31$ and the difference was found to be statistically highly significant $(\mathrm{p}<0.001)$.

Table 13: Distribution of cases according to NICU admission between study and control groups.

\begin{tabular}{|c|c|c|c|c|}
\hline \multirow{2}{*}{$\begin{array}{l}\text { NICU } \\
\text { admission }\end{array}$} & \multicolumn{2}{|c|}{ Study group } & \multicolumn{2}{|c|}{ Control group } \\
\hline & $\begin{array}{l}\text { No. of } \\
\text { cases }\end{array}$ & $\%$ & $\begin{array}{l}\text { No. of } \\
\text { cases }\end{array}$ & $\%$ \\
\hline No & 62 & 62.0 & 88 & 88.0 \\
\hline Yes & 38 & 38.0 & 12 & 12.0 \\
\hline Total & 100 & 100 & 100 & 100 \\
\hline$\chi^{2}$ & 18.027 & & & \\
\hline $\mathrm{P}$ & $<0.001$ & & & \\
\hline
\end{tabular}

According to NICU admission, 50 babies were admitted in NICU. Out of them 38 cases were in study and 12 cases were in control group and this difference was also found to be statistically highly significant $(p<0.001)$. NICU admission was more in oligohydroamnios patients (Table 13).
According to perinatal mortality, out of total 200 deliveries 12 babies expired. 10 of these babies were of study group. This difference was found to be statistically significant $(\mathrm{p}<0.05)$.

Table 14: Distribution of cases according to perinatal mortality between study and control groups.

\begin{tabular}{|l|llll|}
\hline $\begin{array}{l}\text { Perinatal } \\
\text { mortality }\end{array}$ & $\begin{array}{l}\text { Study group } \\
\text { No. of } \\
\text { cases }\end{array}$ & $\%$ & $\begin{array}{l}\text { Control group } \\
\text { No. of } \\
\text { cases }\end{array}$ & $\%$ \\
\hline No & 90 & 90.0 & 98 & 98.0 \\
\hline Yes & 10 & 10.0 & 2 & 2.0 \\
\hline Total & 100 & 100 & 100 & 100 \\
\hline$\chi 2$ & 5.674 & & & \\
\hline P & 0.017 & & & \\
\hline
\end{tabular}

\section{DISCUSSION}

This study was carried out to determine the usefulness of AFI in predicting adverse perinatal outcome. In the study by Ghike et al mean age of women in study group was $24.65 \pm 4.1$ and in controls was $24.00 \pm 4.2$ which is comparable to present study. ${ }^{4}$ In present study $60 \%$ cases in study group and $71 \%$ cases in control group were booked. $40 \%$ and $29 \%$ cases in study and control groups were unbooked respectively. The difference in both groups was found to be statistically insignificant $(\mathrm{p}>0.05)$. Early detection and reference with timely intervention will improve the maternal and perinatal outcome. Majority of women in both groups were primigravida. The mean gravidity in present study is 1.81 and 1.74 in study and control group respectively which is comparable to mean gravidity of 2 in study by Baron et al. ${ }^{5}$ In their study Garmel et al observed that $67 \%$ of women with oligohydramnios were primigravida while we observed $63 \%$ of the women were primigravida in oligohydramnios group which is comparable. ${ }^{6}$

In present study, there was no significant relation between maternal age, ANC booking, education status, residential area, socioeconomic status, gravidity and incidence of oligohydroamnios. However, the results of 
this study cannot be generalized as this study was done on a small sample size.

The mean gestational age in our study was 38.18 weeks in study group and 38.70 weeks in control group which is comparable to mean gestational age of 37.5 weeks in a study by Casey et al (Table 5). ${ }^{7}$ There was no significant difference according to gestational age in study and control groups.

In present study, induction of labour was more in oligohydramnios group that is $52 \%$ compared to $27 \%$ in control group. This difference was found to be statistically highly significant $(\mathrm{p}<0.001)$ (Table 6). Casey et al, in their study also found higher rate of induction in patients with oligohydraminos i.e. $42 \% .^{7}$ In the other studies like Rainford et al, Jandial et al, Gumus et al, also found higher incidence of induction of labour in patients with oligohydraminos. ${ }^{8-10}$ Uteroplacental insufficiency and fetal compromise leading to higher rate of induction in pregnancy with oligohydramnios.

The incidence of meconium stained liquor was high in study group. In our study MSL was present in $46 \%$ of case in study group as compared to $20 \%$ cases in control group. This difference was found to be statistically highly significant $(\mathrm{p}<0.001)$ (Table 7). Similar results are found in study by Jandial et al who found MSL in $48 \%$ of women with oligohydramnios. ${ }^{9}$ Our study is also supported by Crowley et al, who found statistically significant increase in MSL in patients with reduced amniotic fluid volume. ${ }^{11}$ Similarly, Rutherford et al $^{12}$, Ergun et $\mathrm{al}^{13}$, Magann et $\mathrm{al}^{14}$, Casey et $\mathrm{al}^{7}$, also observed that MSL was significantly higher in patients with oligohydroamnios as compared with normal amniotic fluid index. .,12-14 $^{-1}$

This suggests that there is higher incidence of meconium stained liquor and poor placental reserve in oligohydramnios patients. In present study, $54 \%$ cases in study group delivered by LSCS while in control group $23 \%$ cases had LSCS. This difference was found to be statistically highly significant $(\mathrm{p}<0.001)$ (Table 8$)$.

In present study, fetal distress was the most common reason for LSCS. 52.6\% cases in study group and $21.7 \%$ cases in control group underwent LSCS for fetal distress (Table 8). Present result is supported by study done by Jandial et al found that LSCS was done in $56 \%$ cases. ${ }^{9}$ Indication for LSCS was fetal distress in $42 \%$ cases in their study, similar to present study. So, the rate of LSCS for fetal distress was significantly higher in study than in control group.

In the studies conducted by Sarno et al, Conway et al and Sriya, the rate of LSCS for fetal distress was higher in cases when compared to controls which is similar to present observation. ${ }^{15-17}$ Incidence of fetal distress in patients with oligohydraminos are high due to association of oligohydraminos with fetal compromise, head and cord compression, placental insufficiency, IUGR and poor tolerance of labour. So, the discovery of decreased AFV should alert the obstetrician to consider that women is at increased risk and should warrant increased antepartum surveillance and strict vigilance in labour.

In present study $5 \%$ babies in study group were still born as compared to $1 \%$ in control group. 1 baby suffered IUD in study group. In the study conducted by Jandial et $\mathrm{al}^{9}$ who found $4 \%$ still born babies in patients with AFI $<5 \mathrm{~cm}$ which is similar to present study.

Fetal outcome is poor in pregnancies associated with oligohydraminos because of chronic placental insufficiency leading to fetal compromise and fetal distress. So, early detection of oligohydraminos can save babies and improve fetal outcome. Apgar score $\leq 7$ at 1 minute was found in $33 \%$ cases in study group and $18 \%$ cases in control group. Apgar score $\leq 7$ at 5 min was found in $14 \%$ and $4 \%$ cases in study and control groups respectively. The difference was found to be significant $(\mathrm{p}<0.05)$ (Table 11). Present results are supported by study done by Jandial et al, in which Apgar score $<7$ at 5 minute was in $12 \%$ of cases of oligohydramnios group. ${ }^{9}$ Similar results were also found by Rutherford et al. ${ }^{12}$ The mean birth weight observed by us was $2.65 \mathrm{~kg}$ in study group and $2.86 \mathrm{~kg}$ in control group. Birth weight in study group was significantly lower than control group $(\mathrm{p}<0.05)$.

Incidence of low birth weight (birth weight $<2.5 \mathrm{~kg}$ ) observed by us was $42 \%$ in study group while $22 \%$ in control group. This difference was found to be statistically highly significant $(\mathrm{p}<0.001)$ (Table 12). In study by Ghike et al, birth weight $<2.5 \mathrm{~kg}$ was in $51.35 \%$ in study group and $30.16 \%$ in control group which supports the results of present study. ${ }^{4}$ In study by Jandial et al, low birth weight was found in $58 \%$ of cases which is almost similar to present study. ${ }^{9}$ The high incidence of low birth weight in patients having reduced AFI are because of preterm birth, chronic placental insufficiency causing IUGR. Incidence of NICU admissions were observed $38 \%$ in study group as compared to $12 \%$ in control group and difference was statistically highly significant $(\mathrm{p}<0.001)$ (Table 13).

In study done by Bachhav et al NICU admission was $30 \%$ vs $9 \%$ in study and control group which is similar to present study. ${ }^{18}$ Other studies done by Voxman et al, Gumus et al, Jandial et al were also found significant higher rate of NICU admission in patients with oligohydraminos. ${ }^{9,10,19}$ NICU admission are more because of more incidence of preterm births, meconium aspiration, perinatal asphyxia in patients with less AFI. NICU admission is a direct predictor for perinatal morbidity. Thus, AFI in pregnancy can be used as a predictor of perinatal morbidity.

Perinatal deaths in our study was $10 \%$ in study group and $2 \%$ in control group. Among $10 \%$ perinatal deaths in 
study group, $1 \%$ was IUD, 5\% were still birth and $4 \%$ were early neonatal deaths. Perinatal death were significantly higher among study group $(\mathrm{p}<0.05)$ (Table 13). In the study by Jandial et al noted that perinatal death was $10 \%$ in patients with oligohydramnios and their results are similar to present study. ${ }^{9}$ Similar results were found in study by Casey et al reported $6.4 \%$ perinatal death in their study, which was significantly high in patients with oligohydraminos. ${ }^{7}$

\section{CONCLUSION}

Oligohydramnios is associated with a high rate of pregnancy complications and increased perinatal morbidity and mortality. In presence of oligohydramnios, chances of induction, meconium stained liquor, development of fetal distress, LSCS, low 1 and 5 minute Apgar score, low birth weight and perinatal mortality are high.

AFI measurement in antepartum or intrapartum period can help to identify women who need increased antepartum surveillance for pregnancy complications and such women should be managed in a special unit to combat the complications effectively.

\section{Funding: No funding sources}

Conflict of interest: None declared

Ethical approval: Not required

\section{REFERENCES}

1. Brace RA, Wolf EJ. Normal amniotic fluid volume changes throughout pregnancy. Am J Obstet Gynecol. 1989;161:382-8.

2. Fernando A. Practical guide to high risk pregnancy and delivery. 2nd ed Mosby - year Book. Inc. 1993;30:150-59.

3. Phelan JP, Smith CV, Small M. Amniotic fluid volume assessment with four quadrant technique at 36-42 weeks of gestation. J Reprod Med. 1987;32:540-2.

4. Ghike S, Reddy G, Ghike NW. Increasing severity of oligohydramnios: A risk factor for outcome. J South Asian Feder Obst Gynecol. 2013;5(1):8-10.

5. Collen B, Morgan MA, Garite TJ. The impact of amniotic fluid volume assessed intrapartum on perinatal outcome. Am J Obstet Gynecol. 1995; 173:167-74.

6. Garmel SH, Chelmow D, Sha SJ. Oligohydramnios and appropriately grown fetus. Am J Perinatol. 1997; 14:359-63.
7. Casey BM, Mc-Intire DD, Donald D. Pregnancy outcome after diagnosis of oligohydramnios at or beyond 34 weeks of gestation. Am J Obstet Gynecol. 2000;182:902-12.

8. Rainford M, Adair R, Scialli AR, Ghidini A, Spong CY. Amniotic fluid index in the uncomplicated term pregnancy. Prediction of outcome. J Reprod Med. 2001;46(6):589-92.

9. Jandial C, Gupta S, Sharma S, Gupta M. Perinatal outcome after antepartum diagnosis of oligohydramnios at or Beyond 34 weeks of gestation. JK Sci. 2007;9(4):213-4.

10. Gumus II, Koktener A, Turhan NO. Perinatal outcomes of pregnancies with borderline amniotic fluid index. Arch Gynecol Obstet. 2007;276(1):17-9.

11. Crowley P, Harlihy CO, Boylan O. The value of ultrasound measurement of amniotic fluid volume in the management of prolonged pregnancies. $\mathrm{Br} \mathrm{J}$ Obstet Gynecol. 1984;91:444-8.

12. Rutherford SE, Jeffrey $P$, Phelan J, Smith CV, Jacobs N. The four quadrant assessment of amniotic fluid volume. An adjunct to antepartum fetal heart rate testing. Obstet Gynecol. 197;70:353.

13. Ergün A, Atay V, Pabuçcu R, Başer I, Duru NK, Tokaç G. Predictive value of amniotic fluid volume measurements on perinatal outcome. Gynecol Obstet Invest. 1998;45(1):19-23.

14. Magann EF, Chouhan SP, Kinsella MJ. Antenatal testing among 1001 patients at high risk. The role of ultrasonographic estimate of amniotic fluid volume. Am J Obstet Gynecol. 1999;180:1330-6.

15. Sarno AP Jr, Ahn MO, Brar HS. Intrapartum Doppler velocimetry, amniotic fluid volume and fetal heart rae as prediction of subsequent fetal distress. Am J Obstet Gynecol. 1989;16:1508-14.

16. Conway DL, Adkins WB, Shroedere B. Isolated oligohydramnios in the term pregnancy: Is it a clinical entity? J Matern Fetal Med. 1998;7:197-200.

17. Sriya R, Singhai S. Perinatal outcome in patients with amniotic fluid index $<5 \mathrm{~cm}$. J Obstet gynecol India. 2001;51(5):98-100.

18. Bachhav AA, Waikar MR. Low amniotic fluid index at term as a predictor of adverse perinatal outcome. $\mathrm{J}$ Evol Med Dent Sci. 2013;2(38):7221-6.

19. Voxman EG, Tran S, Wing DA. Low amniotic fluid index as a predictor of adverse perinatal outcome. $\mathbf{J}$ Perinatol. 2002;22(4):282-5.

Cite this article as: Chetani M, Deepika, Khajotia S, Kochar S. A Clinical study of amniotic fluid index at or beyond 28 weeks of gestation and its relation to perinatal outcome. Int J Reprod Contracept Obstet Gynecol 2017;6:3280-6. 